NASA Technical Memorandum 83759

\title{
Spectrum/Orbit Utilization Program for Geostationary Satellites
}

Edward F. Miller

Lewis Research Center

Cleveland, Ohio

Prepared for the

Military Communications Conference (MILCOM)

sponsored by the Institute of Electrical and Electronics Engineers

Los Angeles, California, October 21-24, 1984 
SPECTRUM/ORBIT UTILIZATION PROGRAM FOR GEOSTATIONARY SATELLITES

EDWARD F. MILLER

National Aeronautics and Space Administration

Lewis Research Center

Cleveland, Ohio 44135

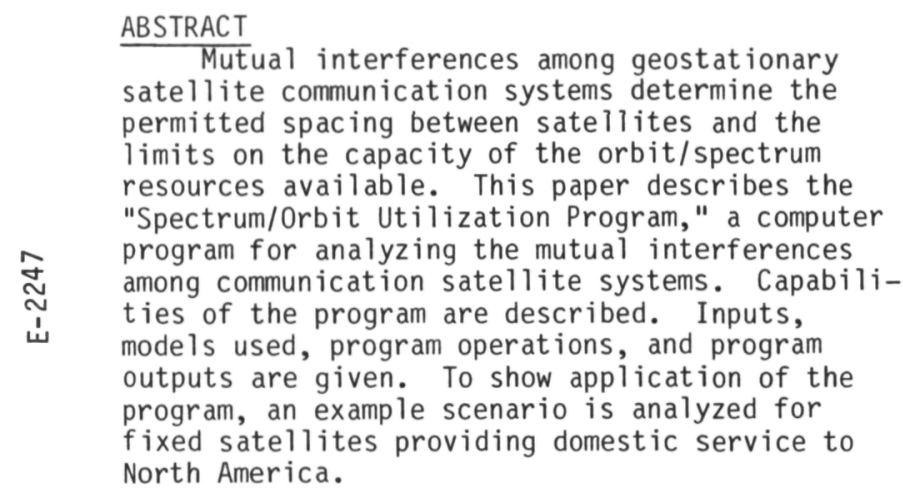

\section{INTRODUCTION}

Current and projected demands on the use of the geostationary orbit/spectrum resource require an analytic tool for determining the interferences among operating and planned communications systems. Prior to development of a satellite system, a detailed analysis must be performed to determine the expected interference environment during operations. Such calculations determine the permitted spacing between satellites and the limits on the capacity of a particular orbit/ spectrum segment.

The Spectrum/Orbit Utilization Program (SOUP) is an analytic computer program for determining the mutual interferences among many geostationary satellite communication systems operating in a given scenario. The major computed outputs are the carrier-to-interference ratios at specified earth station receiver sites. This information allows the determination of the acceptability of planned communication systems. Development of the SOUP analysis program has occurred over the last fourteen years. In 1970 (ref. 1), an early version became operational for evaluation of the general interference problem in satellite communications. In 1971 (ref. 2), the program was adapted for evaluation of the initial DOMSAT applications in the United States. Until 1981, the program underwent a series of minor modifications and improvements (ref. 3). Then in late 1981, SOUP was selected to be the analysis program used at the 1983 Regional Administrative Radio Conference for the broadcasting satellite service at $12 \mathrm{GHz}$ in the western hemisphere. A number of major modelling changes were made, and inputs and outputs were modified to interface with other programs and the several data bases used at the Conference. The current version of SOUP (SOUP5 Version 3.8) is described in a technical manual and a users' manual (refs. 4 and 5).

This paper gives an overview of the Soup analysis program. The basic capabilities of the program are described. The inputs required, the models used, program operations, and the outputs produced are summarized. Application and use of the program are shown by the presentation of an example analysis of a scenario for the fixed satellite service for North America.

\section{CAPABILITIES OF THE ANALYSIS PROGRAM}

SOUP calculates interferences and computes the communications impacts of those interferences. For the general situation depicted in Fig. 1, the feederlink carrier-to-interference ratio $(C / I)$ is calculated at each satellite. At each earth station receive point, the downlink $\mathrm{C} / \mathrm{I}$ is calculated, taking into account interferences from all other satellites in the geostationary orbit. Of course, only those satellites operating at nearby frequencies are entered into the scenario.

The program, as presently configured, can handle up to 300 downlink service areas and 300 feederlink service areas, where each service area pair is associated with a satellite in the geostationary orbit. The downlink service area and the feederlink service area associated with a single satellite are not required to be the same. There can be up to 1600 feederlink transmitter sites and 4500 earth station receiving sites. Dimensions of the arrays in the program can be increased at the expense of additional memory requirements and longer run times.

When the total C/I is calculated at an earth station receiver, account is taken of interferers that are co-channel, adjacent channel, and second 
adjacent channel. Downlink and feederlink interferences are mathematically combined, and the total interference is compared to a given requirement that varies with modulation type, grade of service, and other parameters. Earth station receivers that exceed the required C/I are said to have a positive margin, those that fail to meet the requirement have a negative margin.

For some systems, communications performance may be specified in terms other than C/I, e.g., picowatts of noise added to a telephone channel or bit error rate in a digital system. In these cases, a receiver transfer constant is used to transform from a C/I ratio to an output performance measure.

The calculations performed for each test point have technical parameters that are variable for each service area. Rain attenuation and other propagation effects can be taken into account. Either circular or linear polarization can be used. Additional quantities calculated include power flux-density, received power, received carrier-to-noise ratio, and spacecraft power.

\section{PROGRAM DESCRIPTION}

The SOUP analys is program acts upon a number of input data files, performs calculations, and produces the outputs that indicate the mutual interferences in the satellite systems under consideration. The system overview of the program is Fig. 2. Subsequent sections will discuss the inputs, the mathematical models used, operations, and the outputs.

SOUP is written in FORTRAN and has been found to be easily transferable from machine to machine. It has been run on IBM 370, VAX, PRIME-400, and SIEMENS computers. Full details of the program are given in Refs. 4 and 5 .

Inputs

To run the program, complete descriptions are required for the satellite communication systems. Elements needed are shown in Tables I and II. The listings in the tables are not intended to be exhaustive, but rather they are complete enough to show the high degree of detail needed to specify a scenario for analysis. If the required input data are not known, good engineering judgment can be used as the basis for assumed values.

Inputs can be specified on a global basis, where, for example, all earth station receivers might have the same characteristics. However, provisions are made for overrides, whereby parameter values may be specified differently at each location which allows, for example, different antenna sizes or noise figures at different locations.

Some of the required input data is computer generated outside of SOUP. For example, the user may desire to cover selected service areas on the earth with minimum area elliptical beams. Characteristics of the ellipses may be generated by a separate program (ref.6) and then stored in the up and down ellipse files for use as inputs to SOUP.
Modeling Used

In this section, an overview is given of the mathematical models used in the SOUP analysis program. It is intended only to convey a general understanding of the program elements and to indicate the flexibility of the models. Consequently, full details are not given. Reference 4 gives more complete documentation of the models.

Geometric Models Spherical geometry is used to calculate parameters such as slant range, elevation angle, and the antenna off-axis angles as shown in Fig. 3 . If a ground point and a satellite are determined to be over the horizon with respect to each other, no interference calculations are performed. Antenna pointing errors are taken into account by increasing the off-axis angle by the pointing error when carrier signals are calculated, and by decreasing the off-axis angle when interferences are calculated. This results in conservative or worst-case calculations of (C/I) ratios. Rotational errors of elliptical antennas are not modelled.

Antenna Gain Patterns Antenna beams are assumed to be either elliptical or circular and may be specified by either their half power beamwidths or diameters. Co-polarized and crosspolarized gains are both modelled. A typical antenna gain characteristic is shown in Fig. 4. The segments of the off-axis gain curves of the type shown in Fig. 4 are mathematically modelled as constants, polynomials, exponential functions, or logarithmic functions. Antenna gain characteristics may also be input as gain contours on the surface of the earth (for satellite antennas) and as range measured antenna characteristics in spherical coordinates.

In the case of an elliptical spacecraft antenna, the off-axis gain is calculated by first determining an equivalent half power beamwidth in the off-axis direction. Then the gain is computed by using that half power beamwidth in the appropriate antenna gain model.

Protection Ratios In a communication system, the protection ratio is defined as the ratio at the receiver input of the wanted signal power to the aggregate interfering signal power required to meet a given quality of service. The protection ratio varies as a function of wanted and interfering signal types, the modulations used, the frequency difference between wanted and interfering signals, and a number of other parameters. In the SouP program, the protection ratio can be modelled as a template (fig. 5 is typical) or as discrete values for the co-channel, adjacent channel, and second adjacent channel interference cases.

Transmit Power Space station and feederlink transmit powers may be specified in terms of EIRP, Watts delivered to the antenna, resultant power flux density, or resultant carrier-tonoise ratio. For whatever form is specified, the other parameters are calculated and supplied to the user. 
Propagation Model The current CCIR propagation model is incorporated as a subroutine. Other propagation models are available as options. Rain attenuation and depolarization are used in SOUP. Calculations may be run either for clear weather or for propagation effects taken into account, i.e., with rain.

Rain attenuation is used to calculate transmitter powers required, while both rain attenuation and depolarization effects are used to calculate received powers.

C/I calculations are done on a worst case basis. For feederlinks, faded $C$ and unfaded I are assumed. For the downlink, at a particular earth station receiver site, both the $C$ and the I are assumed to experience fading. The magnitude of the fade for each, of course, depends on the elevation angle to the source.

Channelization Calculations in SOUP may be performed for individual channels or for groups of channels. For individual channels, exact center frequencies are used, while for groups of channels, a typical frequency is used.

Aggregate and Total Interference and Margin Interferences are calculated in five categories: co-channel, upper and lower adjacent channel, and upper and lower second adjacent channel. Within each category, multiple interferers are assumed to add on a power basis to form the aggregate interference in that category. The aggregate uplink C/I and the aggregate downlink C/I are combined to form the total aggregate C/I in a category.

Each category has a protection ratio associated with it. The difference between the C/I and the protection ratio is the protection margin. Thus, a total aggregate co-channel protection margin is calculated. To combine all interference effects, the total aggregate equivalent protection margin $M$ is calculated.

$$
M=-10 \log \left[\sum_{i=1}^{5} 10^{-\left(M_{i} / 10\right)}\right]
$$

$$
\begin{array}{ll}
\text { where } & \\
M_{1} & \begin{array}{c}
\text { total aggregate co-channel protection } \\
\text { margin, in } \mathrm{dB} .
\end{array} \\
\text { total aggregate adjacent channel pro- } \\
\text { tection margins for the upper and } \\
\text { lower adjacent channels respectively, } \\
\text { in dB. } \\
\text { total aggregate second adjacent channel } \\
\text { protection margins for the upper and } \\
\text { lower second adjacent channels } \\
\text { respectively, in } \mathrm{dB} .
\end{array}
$$

The adjective "equivalent" indicates that the protection margins for all interference sources from the adjacent and second adjacent channels as well as co-channel interference sources have been included.

Interference Matrix An interference matrix is available to allow the inhibiting of interference calculations between systems serving selected service areas. This feature is useful in removing from the calculations interference situations that might be solved by other means such as, bilateral coordination.

Program 0perations

The block diagram in Fig. 2 shows three major program elements $\mathrm{P} 1, \mathrm{P} 2$, and P3. Their functions are:

P1 - Selects the data from the data base which are needed for the run and assembles them into a form usable by programs P2 and P3; echo prints the selected data while checking and editing them for completeness and consistency.

P2 - Performs "non-cross" calculations: unit conversions (e.g., dB to numerics); transformation to Cartesian coordinates; calculations of protection ratios by interference category; determination of interference categories by channel; computations of on-axis gains, transmitter power, etc.

P3 - Performs "cross" calculations (i.e., for up, each satellite vs. all feederlink test points; for down, each earth station receiver test point vs. all satellites). Calculations performed include: gain, received signal power, attenuation, C/I and margins. Produces summary aggregate interference reports for up, down, and total.

Program Outputs

Major outputs of the SOUP program include (a) summary reports of the interference for feederlinks, downlinks, and total, (b) detailed reports giving results for each link calculation performed (all test points in all service areas), and (c) the binary output report which contains all input data and all calculated results (used for generating as yet unspecified output reports). An example summary report is given in Table III and segments of detail reports 1 and 2 are given in Table IV. (The numerical results given in Tables III and IV are for a fixed satellite service scenario discussed in the next section of this paper.)

USES AND APPLICATIONS OF THE PROGRAM

The SOUP analytic program was used as the official analysis program at the 1983 Regional Administrative Radio Conference (RARC). In that capacity, the program calculated the performances of tentative systems to allow evaluations of the suitability of alternative spectrum/orbit plans. Currently, the program is being used by the International Frequency Registration Board for a channel by channel analysis of the RARC-83 plan. Additionally the U.S. delegation to RARC -83 used SoUP to evaluate different planning alternatives prior to and during the Conference. The FCC, NTIA, NASA, and several communications satelite related corporations used and are continuing to use SOUP for mutual interference analyses of communication satellite systems.

As an example of current applications of the SOUP analysis program, a scenario in the fixed satellite service will be evaluated. The scenario considers domestic satellite service to North America (United States, Canada, and Mexico). While the satellite locations may be near to what is currently operational or 
planned, the actual details of real satellites were not included. Common assumptions were made for the different satellite systems to simplify data entry. Table $V$ lists the major assumed characteristics.

The summary of results in Table III shows for each test point, in each service area the C/I for co-channel, adjacent channel, and second adjacent channel interferers. The positive total margins indicate acceptable operation for the $\mathrm{C} / \mathrm{I}$ criterion used. Where the margins are slightly negative, the C/I criterion has not been met, and slightly degraded performance will occur. The detail reports in Table IV give values for specific parameters in the link calculations, e.g., carrier to noise ratio, received power flux density, antenna gains, transmitter power, and slant range.

\section{CONCLUDING REMARKS}

This paper has given an overview of the Spectrum/Orbit Utilization Program (SOUP) for analyzing the mutual interferences among communication systems having satellites in geostationary orbits. Capabilities of the program were described. Inputs, models used, program operations, and program outputs were given. Application of the program was shown by analyzing an example scenario in the fixed satellite service for domestic service within North America.

\section{REFERENCES}

1. "Orbit/Spectrum Utilization Study," Volume IV, General Electric, Document No. 70SD 4293, 31 December 1970

2. "Spectrum Orbit Utilization Program, User's Manual," by P. Sawitz and N. Shusterman, 16 May 1974, ORI Technical Report 830.

3. "Spectrum/Orbit Utilization Program User and Programmer's Manual," Volumes I and II, Davidson, J. and Sawitz, P., ORI, Contract NAS3-22884, 9 September 1981

4. "Spectrum Orbit Utilization Program Documentation, SOUP5 Version 3.8 Technical Manual," Davidson, J., Ottey, H.R., Sawitz, P. and Zusman, F.S., ORI. Prepared under Contract No. NAS3-22885 for NASA LeRC, 7 December 1983

5. "Spectrum Orbit Utilization Program Documentation, SOUP5 Version 3.8 User's Manual," Volumes I and II, Davidson, J., Ottey, H.R., Sawitz, P. and Zusman, F.S. ORI Tech. Rpt. No. 2273. Prepared under Contract No. NAS3-22885 for NASA LeRC, 29 June 1984.

6. "A Method for Determining the Minimum Elliptical Beam of a Satellite Antenna," Akima, H., NTIA Report 81-88, 0ctober 1981 
TABLE I. - INPUT CHARACTERISTICS REQUIRED FOR DOWNLINKS

\begin{tabular}{l} 
System Characteristics: \\
Type of Modulation \\
Frequency Band \\
Number of Channels \\
Necessary Bandwidth \\
Channel Spacing \\
Guard Bands \\
Lower Band Edge \\
Upper Band Edge \\
Carrier to Noise Ratio \\
(xx percent of worst month) \\
Power Flux Density \\
(Edge of coverage area, \\
for xx percent of worst month) \\
Protection Ratio \\
(Required overall carrier-to-interference \\
ratio for xx percent of worst month) \\
Co-Channel \\
$\quad$ Adjacent Channel \\
$\quad$ Second Adjacent Channel \\
Satellite Characteristics: \\
Satellite Orbital Position \\
Transponder RF Power \\
(Delivered to antenna input) \\
EIRP Difference Between Beam Axis \\
and Edge-of-Coverage \\
Polarization \\
Transmitting Antenna Reference Pattern \\
Transmitting Antenna Efficiency \\
Pointing Accuracy of Satellite Antenna \\
Receive Station Characteristics: \\
Receiving Antenna Half-Power-Beamwidth \\
Receiving Antenna Polarization \\
Receiving Antenna Reference Pattern \\
(System Noise Temperature) \\
Latitude, Longitude, Elevation \\
Rain Zone \\
\hline
\end{tabular}

TABLE II. - INPUT CHARACTERISTICS REQUIRED FOR FEEDERLINKS

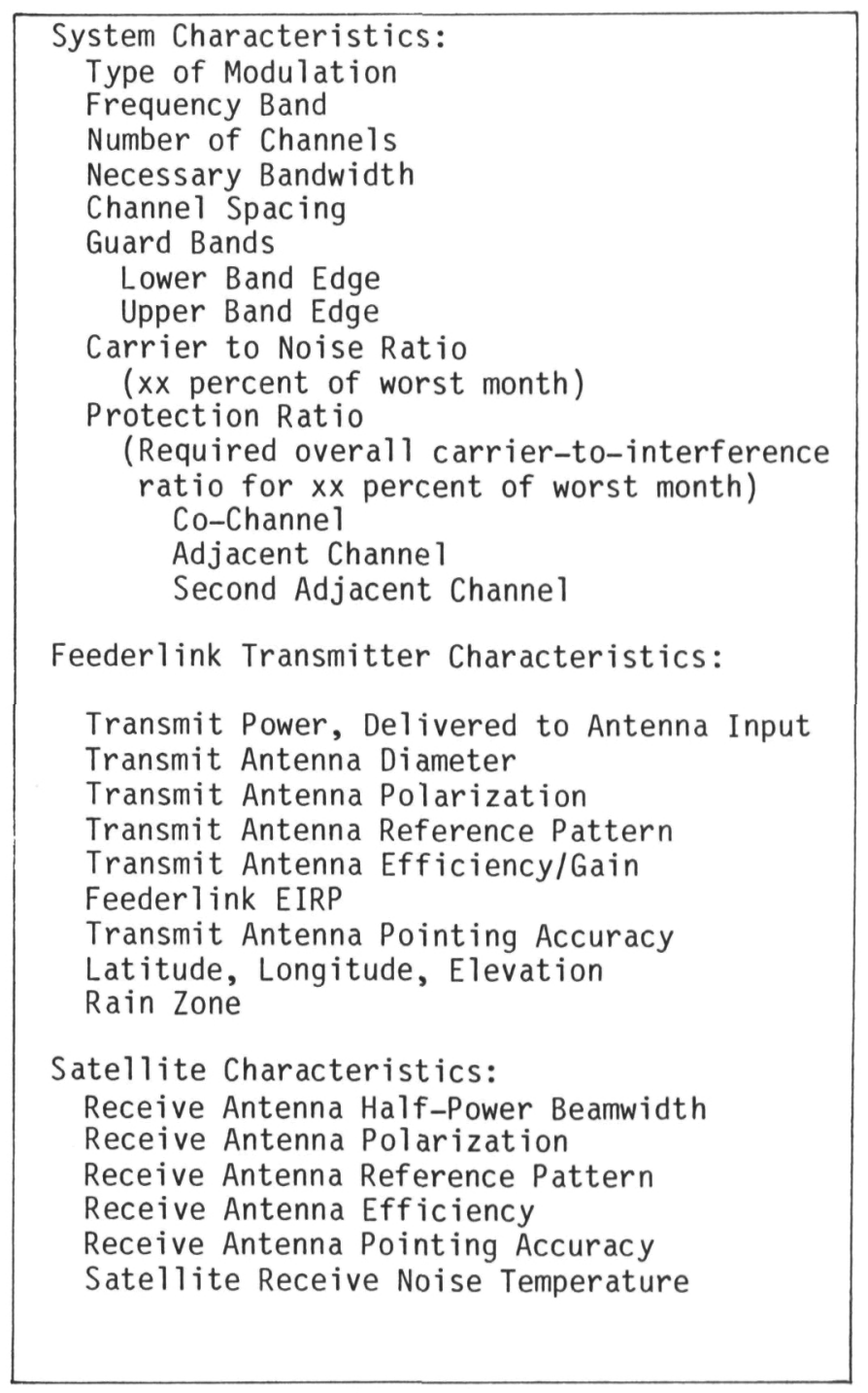


TABLE III — - AGGREGATE TOTAL SUMMARY FOR FSSNAMO2

\begin{tabular}{|c|c|c|c|c|c|c|c|c|c|c|c|c|c|c|c|}
\hline $\begin{array}{l}\text { SERV ICE } \\
\text { AREA }\end{array}$ & $\begin{array}{l}\text { SAT } \\
\text { LONG }\end{array}$ & $\begin{array}{l}\text { TEST } \\
\text { LAT- }\end{array}$ & $\begin{aligned} & \text { POINT } \\
& \text { LONG }\end{aligned}$ & $\begin{array}{l}\mathrm{CO}-\mathrm{CH} \\
\mathrm{C} / \mathrm{I}\end{array}$ & $\begin{array}{l}\text { NEL } \\
\text { RGN }\end{array}$ & $\begin{array}{l}\text { UPPE } \\
\text { C/I }\end{array}$ & $\begin{array}{l}\text { R-ADJ } \\
\text { MARGN }\end{array}$ & $\begin{array}{l}\text { LOWE } \\
\mathrm{C} / \mathrm{I}\end{array}$ & $\begin{array}{l}\text { E R ADJ } \\
\text { MARGN }\end{array}$ & $\begin{array}{l}\text { NEXT- } \\
\mathrm{C} / \mathrm{I}\end{array}$ & $\begin{array}{l}\text {-UPPER } \\
\text { MARGN }\end{array}$ & $\begin{array}{l}\mathrm{LOl} \\
\mathrm{C} / \mathrm{I}\end{array}$ & $\begin{array}{l}\text { ADJ } \\
\text { ARGN }\end{array}$ & & $\begin{array}{l}\text { TOTAL } \\
\text { MARGIN }\end{array}$ \\
\hline NNTOOOOI & $\begin{array}{l}-104.5 \\
-104.5 \\
-104.5 \\
-104.5 \\
-104.5 \\
-104.5 \\
-104.5 \\
-104.5 \\
-104.5 \\
-104.5\end{array}$ & $\begin{array}{l}70.0 \\
70.0 \\
47.0 \\
43.0 \\
41.7 \\
44.6 \\
49.0 \\
48.3 \\
52.6 \\
60.3\end{array}$ & $\begin{array}{r}-141.0 \\
-64.8 \\
-52.5 \\
-60.0 \\
-82.6 \\
-81.2 \\
-106.0 \\
-123.9 \\
-132.2 \\
-141.0\end{array}$ & $\begin{array}{l}19.1 \\
18.8 \\
19.1 \\
18.8 \\
18.5 \\
19.0 \\
19.2 \\
18.7 \\
19.0\end{array}$ & $\begin{array}{l}-0.9 \\
-1.2 \\
-0.9 \\
-1.2 \\
-1.5 \\
-1.0 \\
-0.8 \\
-1.3 \\
-1.0 \\
-0.8\end{array}$ & $\begin{array}{l}99.0 \\
99.0 \\
99.0 \\
99.0 \\
99.0 \\
99.0 \\
99.0 \\
99.0 \\
99.0 \\
99.0\end{array}$ & $\begin{array}{l}99.0 \\
99.0 \\
99.0 \\
99.0 \\
99.0 \\
99.0 \\
99.0 \\
99.0 \\
99.0 \\
99.0\end{array}$ & $\begin{array}{l}99.0 \\
99.0 \\
99.0 \\
99.0 \\
99.0 \\
99.0 \\
99.0 \\
99.0 \\
99.0 \\
99.0\end{array}$ & $\begin{array}{l}99.0 \\
99.0 \\
99.0 \\
99.0 \\
99.0 \\
99.0 \\
99.0 \\
99.0 \\
99.0 \\
99.0\end{array}$ & $\begin{array}{l}-3.0 \\
-3.0 \\
-3.0 \\
-3.0 \\
-3.0 \\
-3.0 \\
-3.0 \\
-3.0 \\
-3.0 \\
-3.0\end{array}$ & $\begin{array}{l}16.9 \\
16.9 \\
16.9 \\
16.9 \\
16.9 \\
16.9 \\
16.9 \\
16.9 \\
16.9 \\
16.9\end{array}$ & $\begin{array}{l}-3.0 \\
-3.0 \\
-3.0 \\
-3.0 \\
-3.0 \\
-3.0 \\
-3.0 \\
-3.0 \\
-3.0 \\
-3.0\end{array}$ & $\begin{array}{l}17.0 \\
17.0 \\
17.0 \\
17.0 \\
17.0 \\
17.0 \\
17.0 \\
17.0 \\
17.0 \\
17.0\end{array}$ & $\begin{array}{l}* * * * \\
* * * * \\
* * * * \\
* * * * \\
* * * * \\
* * * * \\
* * * \\
* * * \\
* * * * \\
* * * * \\
* * *\end{array}$ & $\begin{array}{l}-1.0 \\
-1.3 \\
-1.1 \\
-1.4 \\
-1.6 \\
-1.1 \\
-0.9 \\
-1.4 \\
-1.1 \\
-1.0\end{array}$ \\
\hline 0001 & $\begin{array}{l}-108.0 \\
-108.0 \\
-108.0 \\
-108.0 \\
-108.0 \\
-108.0 \\
-108.0 \\
-108.0 \\
-108.0 \\
-108.0\end{array}$ & $\begin{array}{l}70.0 \\
70.0 \\
47.0 \\
43.0 \\
41.7 \\
44.6 \\
49.0 \\
48.3 \\
52.6 \\
60.3\end{array}$ & $\begin{array}{r}-141.0 \\
-64.8 \\
-52.5 \\
-60.0 \\
-82.6 \\
-81.2 \\
-106.0 \\
-123.9 \\
-132.2 \\
-141.0\end{array}$ & $\begin{array}{l}18.8 \\
18.3 \\
19.0 \\
18.9 \\
18.9 \\
19.2 \\
19.3 \\
19.0 \\
19.1 \\
19.0\end{array}$ & $\begin{array}{l}-1.2 \\
-1.7 \\
-1.0 \\
-1.1 \\
-1.1 \\
-0.8 \\
-0.7 \\
-1.0 \\
-0.9 \\
-1.0\end{array}$ & $\begin{array}{l}99.0 \\
99.0 \\
99.0 \\
99.0 \\
99.0 \\
99.0 \\
99.0 \\
99.0 \\
99.0 \\
99.0\end{array}$ & $\begin{array}{l}99.0 \\
99.0 \\
99.0 \\
99.0 \\
99.0 \\
99.0 \\
99.0 \\
99.0 \\
99.0 \\
99.0\end{array}$ & $\begin{array}{l}99.0 \\
99.0 \\
99.0 \\
99.0 \\
99.0 \\
99.0 \\
99.0 \\
99.0 \\
99.0 \\
99.0\end{array}$ & $\begin{array}{l}99.0 \\
99.0 \\
99.0 \\
99.0 \\
99.0 \\
99.0 \\
99.0 \\
99.0 \\
99.0 \\
99.0\end{array}$ & $\begin{array}{l}-3.0 \\
-3.0 \\
-3.0 \\
-3.0 \\
-3.0 \\
-3.0 \\
-3.0 \\
-3.0 \\
-3.0 \\
-3.0\end{array}$ & $\begin{array}{l}16.9 \\
16.9 \\
16.9 \\
16.9 \\
16.9 \\
16.9 \\
16.9 \\
16.9 \\
16.9 \\
16.9\end{array}$ & $\begin{array}{l}-3.0 \\
-3.0 \\
-3.0 \\
-3.0 \\
-3.0 \\
-3.0 \\
-3.0 \\
-3.0 \\
-3.0 \\
-3.0\end{array}$ & $\begin{array}{l}17.0 \\
17.0 \\
17.0 \\
17.0 \\
17.0 \\
17.0 \\
17.0 \\
17.0 \\
17.0 \\
17.0\end{array}$ & $\begin{array}{l}* * * * \\
* * * * \\
* * * * \\
* * * * \\
* * * * \\
* * * \\
* * * \\
* * * * \\
* * * * \\
* * * * \\
* * * *\end{array}$ & $\begin{array}{l}-1.3 \\
-1.8 \\
-1.2 \\
-1.2 \\
-1.2 \\
-1.0 \\
-0.8 \\
-1.1 \\
-1.1 \\
-1.1\end{array}$ \\
\hline ANTOOOL & $\begin{array}{l}-1111.5 \\
-1111.5 \\
-1111.5 \\
-111.5 \\
-111.5 \\
-111.5 \\
-111.5 \\
-111.5 \\
-111.5 \\
-1111.5\end{array}$ & $\begin{array}{l}70.0 \\
70.0 \\
47.0 \\
43.0 \\
41.7 \\
44.6 \\
49.0 \\
48.3 \\
52.6 \\
60.3\end{array}$ & $\begin{array}{r}-141.0 \\
-64.8 \\
-52.5 \\
-60.0 \\
-82.6 \\
-81.2 \\
-106.0 \\
-123.9 \\
-132.2 \\
-141.0\end{array}$ & $\begin{array}{l}20.2 \\
20.5 \\
20.5 \\
20.8 \\
21.0 \\
21.1 \\
19.9 \\
20.4 \\
20.8\end{array}$ & $\begin{array}{r}0.9 \\
0.2 \\
0.5 \\
0.5 \\
0.8 \\
1.0 \\
1.1 \\
-0.1 \\
0.4 \\
0.8\end{array}$ & $\begin{array}{l}99.0 \\
99.0 \\
99.0 \\
99.0 \\
99.0 \\
99.0 \\
99.0\end{array}$ & $\begin{array}{l}99.0 \\
99.0 \\
99.0 \\
99.0 \\
99.0 \\
99.0 \\
99.0 \\
99.0 \\
99.0\end{array}$ & $\begin{array}{l}99.0 \\
99.0 \\
99.0 \\
99.0 \\
99.0 \\
99.0 \\
99.0 \\
99.0 \\
99.0\end{array}$ & $\begin{array}{l}99.0 \\
99.0 \\
99.0 \\
99.0 \\
99.0 \\
99.0 \\
99.0 \\
99.0 \\
99.0 \\
99.0\end{array}$ & $\begin{array}{l}-3.0 \\
-3.0 \\
-3.0 \\
-3.0 \\
-3.0 \\
-3.0 \\
-3.0 \\
-3.0 \\
-3.0 \\
-3.0\end{array}$ & $\begin{array}{l}16.9 \\
16.9 \\
16.9 \\
16.9 \\
16.9 \\
16.9 \\
16.9 \\
16.9 \\
16.9 \\
16.9\end{array}$ & $\begin{array}{l}-3.0 \\
-3.0 \\
-3.0 \\
-3.0 \\
-3.0 \\
-3.0 \\
-3.0 \\
-3.0 \\
-3.0\end{array}$ & $\begin{array}{l}17.0 \\
17.0 \\
17.0 \\
17.0 \\
17.0 \\
17.0 \\
17.0 \\
17.0 \\
17.0 \\
17.0\end{array}$ & $\begin{array}{l}* * * \\
* * * * \\
* * * \\
* * * \\
* * * \\
* * * \\
* * * \\
* * * \\
* * * \\
* * * \\
* * * * \\
* * *\end{array}$ & $\begin{array}{r}0.7 \\
-0.0 \\
0.3 \\
0.3 \\
0.6 \\
0.8 \\
0.9 \\
-0.2 \\
0.2 \\
0.6\end{array}$ \\
\hline
\end{tabular}




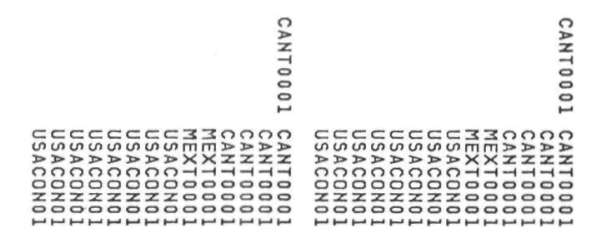

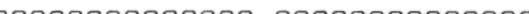

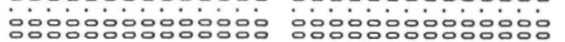

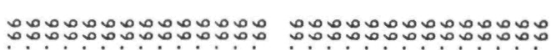

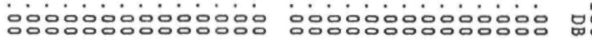

ได

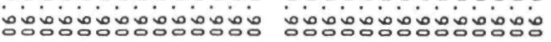

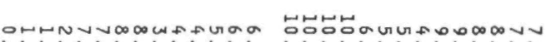

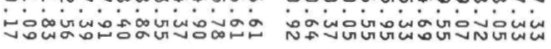

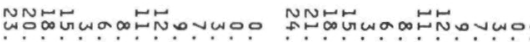
ond

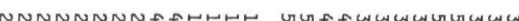

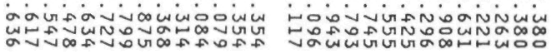
Еีस

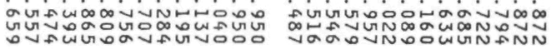

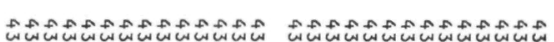

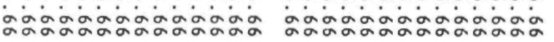

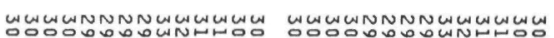

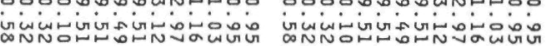
00000000000000 00000000000000 유류

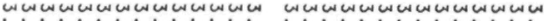
政

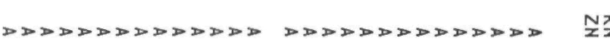

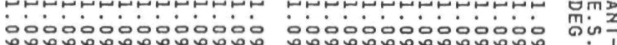

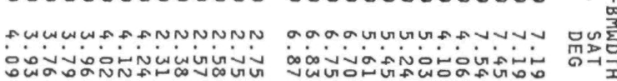

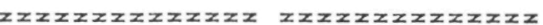

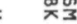

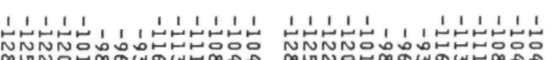

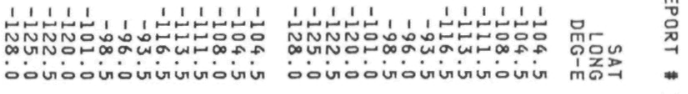

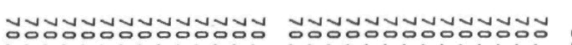
00000000000000 0000000000000

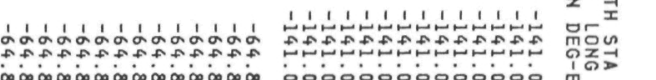

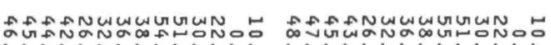
जคoN

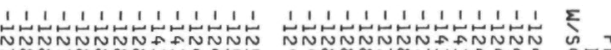

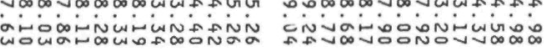

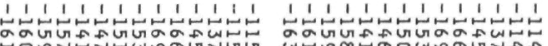

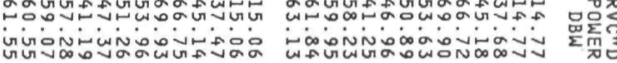

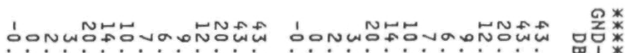

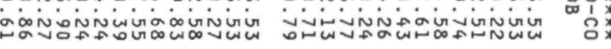

0.0000000000 0000000000000000000000000000

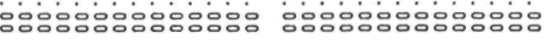

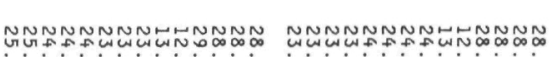

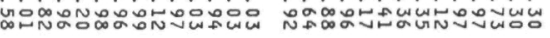

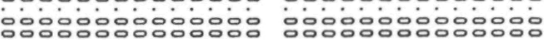

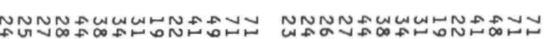

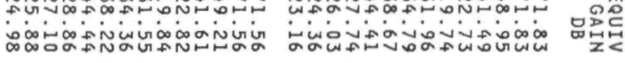

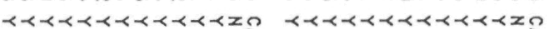

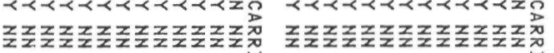

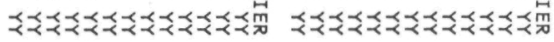

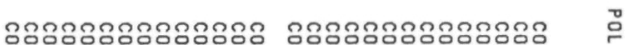

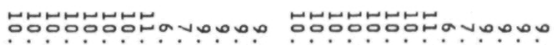

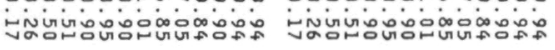


TABLE 5

A DOMESTIC SATELLITE SCENARIO FOR NORTH AMERICA

PARAMETER

U.S. SATELLITE LOCATIONS

CANADA SATELLITE LOCATIONS

MEXICO SATELLITE LOCATIONS

SERVICE AREAS

FREQUENCIES

PK - PK FREQUENCY DEVIATION

NECESSARY BANDWIDTH

CHANNEL SPACING

PROTECTION RATIOS

FEEDERLINK TRANSMITTER ANTENNA

SATELLITE ANTENNA

SATELLITE ANTENNA BEAM EDGE LOSS

EARTH STATION RECEIVE ANTENNA
VALUE

$93.5,96,98.5,101,120,122.5,125,128$

$104.5,108,111.5$

$113.5,116.5$

MINIMUM AREA ELLIPSES THAT COVER EACH COUNTRY

$6 \mathrm{GHz}$, FEEDERLINK

$4 \mathrm{GHz}$, DOWNLINK

$24 \mathrm{MHz}$

$36 \mathrm{MHz}$

$40 \mathrm{MHZ}$, SAME POL.; $20 \mathrm{MHZ}$, OPP. POL.

$20 \mathrm{DB}$, CO-CHANNEL

$12 \mathrm{DB}$, ADJACENT CHANNEL

$-20 \mathrm{DB}$, SECOND ADJACENT CHANNEL

5 M., DIAMETER

CCIR REFERENCE PATTERN, 32-25 LOG $\emptyset$ REQUIRED ELLIPSE, RECEIVE AND TRANSMIT CCIR REFERENCE PATTERN, RPT. 558-2

$3 \mathrm{DB}$

5 M., DIAMETER

CCIR REFERENCE PATTERN, 32-25 LOG $\emptyset$ 


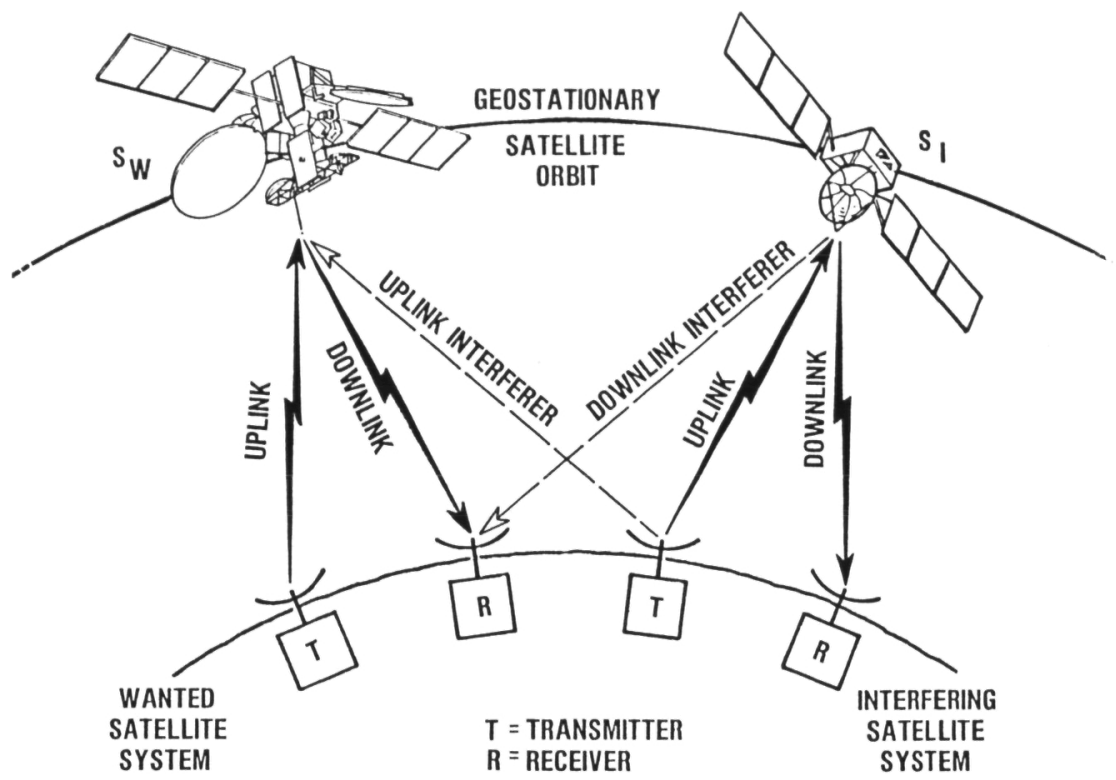

Figure 1. - Simplified model. 


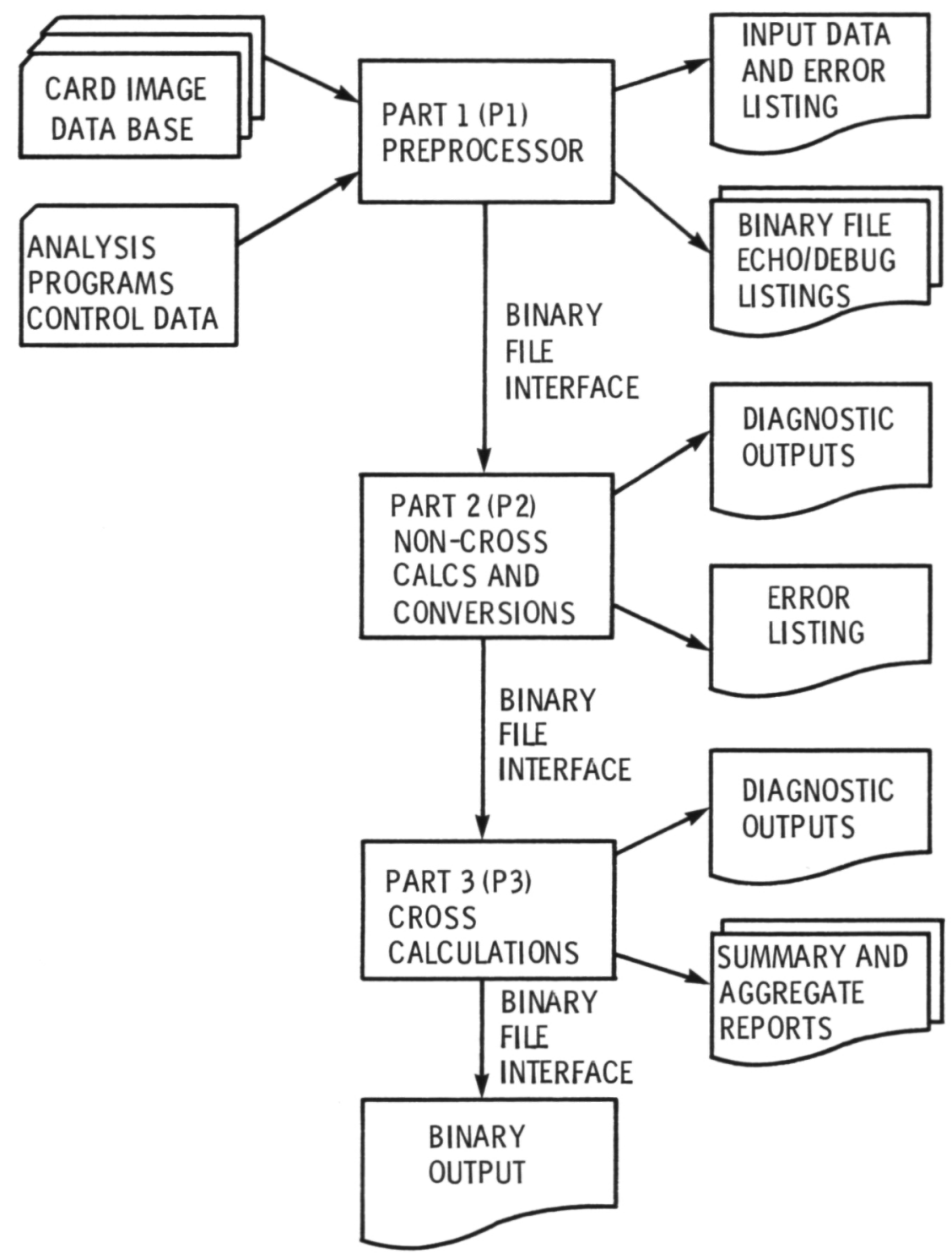

Figure 2 - SOUP5 Overview. 


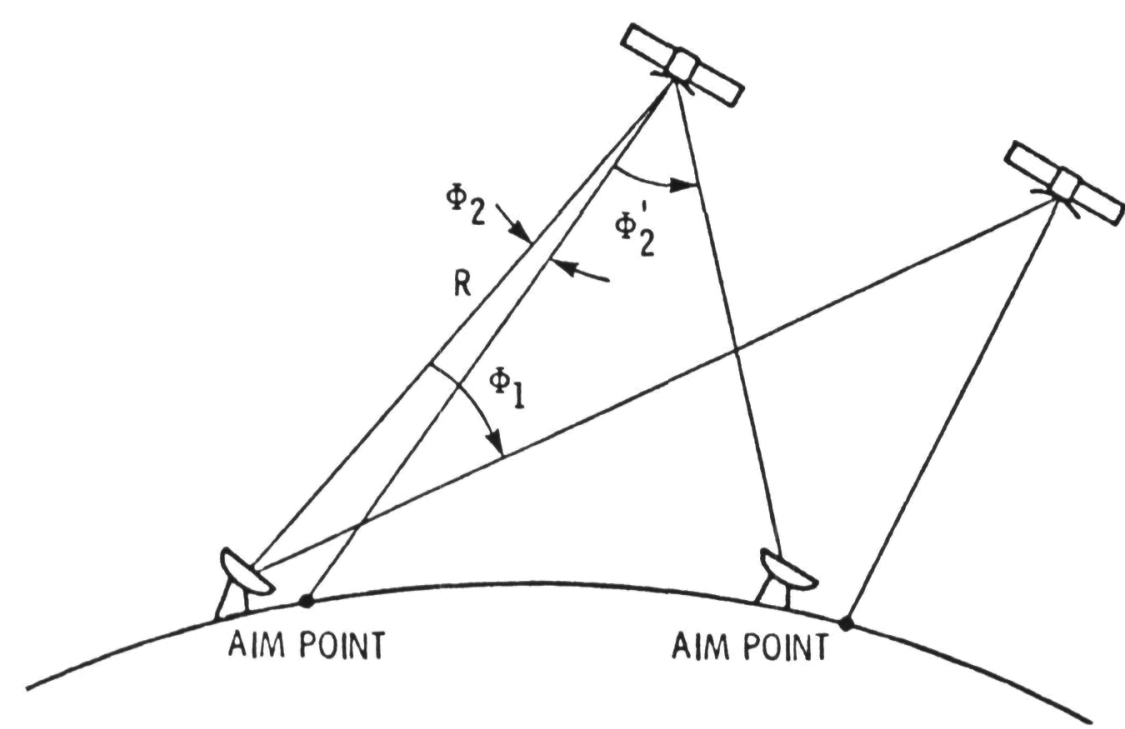

Figure 3. - Simplified geometry for calculation of range (R) and off-axis angles $(\Phi)$.

$\Phi_{1}=$ Off-axis angle to non-target satellite.

$\Phi_{2}$ - Off-axis angle to test point in desired service area.

$\Phi_{2}^{\prime}=$ Off-axis angle to test point in non-target service area.

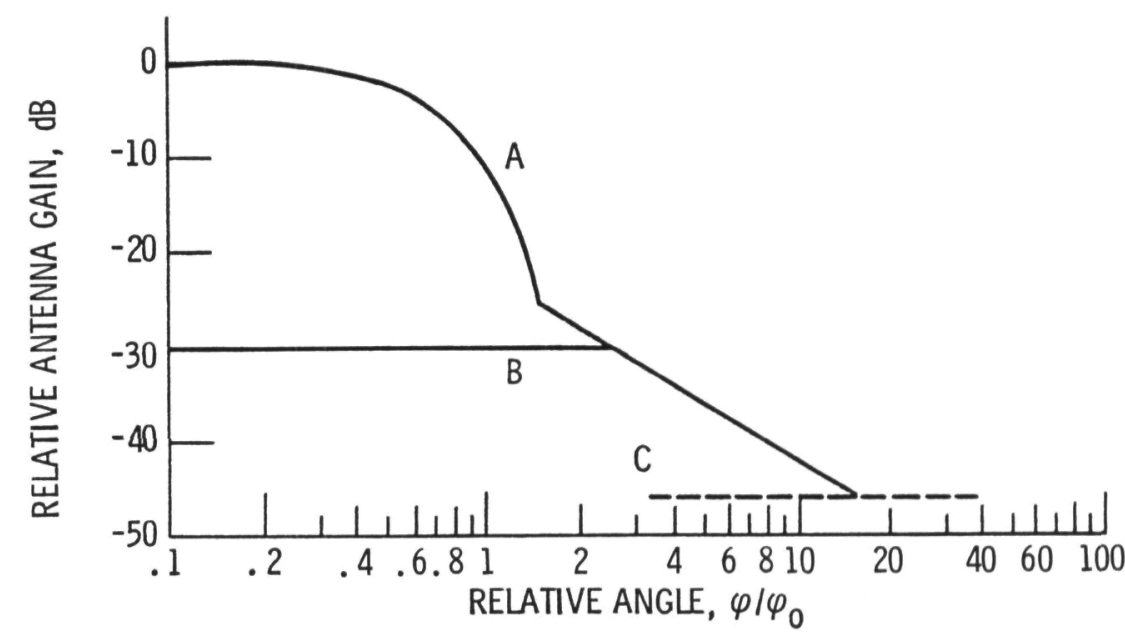

Figure 4. - Reference patterns for co-polar and cross-polar components for satellite transmitting antenna.

CURVE A: CO-POLAR COMPONENT (dB RELATIVE TO MAIN BEAM GAIN)

$-12\left(\varphi / \varphi_{0}\right)^{2} \quad$ FOR $0 \leqslant\left(\varphi / \varphi_{0}\right) \leqslant 1.45$

$-\left(22+20 \log _{10}\left(\varphi / \varphi_{0}\right) \quad\right.$ FOR $1.45<\left(\varphi / \varphi_{0}\right)$

AFTER INTERSECTION WITH CURVE C : AS CURVE C

CURVE B : CROSS-POLAR COMPONENT ( $\mathrm{dB}$ RELATIVE TO MAIN BEAM GAIN)

$-30 \quad$ FOR $0 \leqslant\left(\varphi / \varphi_{0}\right) \leqslant 2.51$

AFTER INTERSECTION WITH CO-POLAR PATTERN : AS CO-POLAR PATTERN

CURVE C : MINUS THE ON-AXIS GAIN 


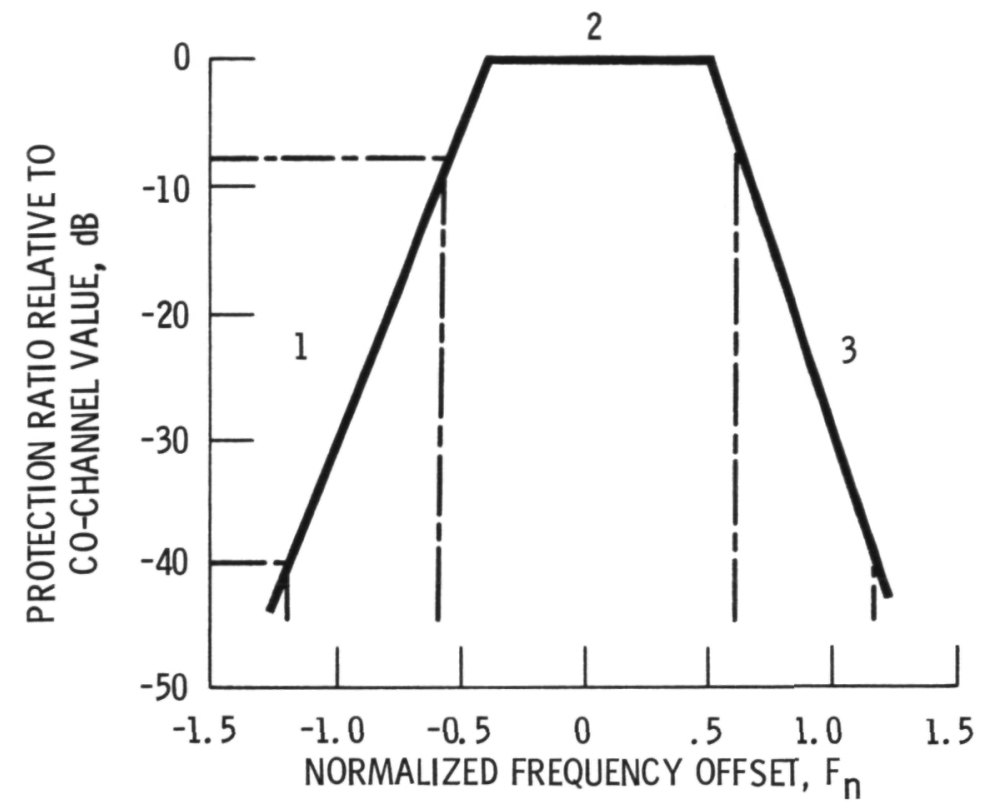

(FREQUENCY OFFSET/CARSON'S RULE BANDWIDTH)
1. $\quad 52.8 F_{n}+24 d B$
$F_{n}<-0.45$
2. $0.0 \quad \mathrm{~dB} \quad-0.45 \leq \mathrm{F}_{\mathrm{n}} \leq 0.45$
3. $-52.8 F_{n}+24 d B \quad F_{n}>0.45$

Figure 5. - Protection ratio template. 


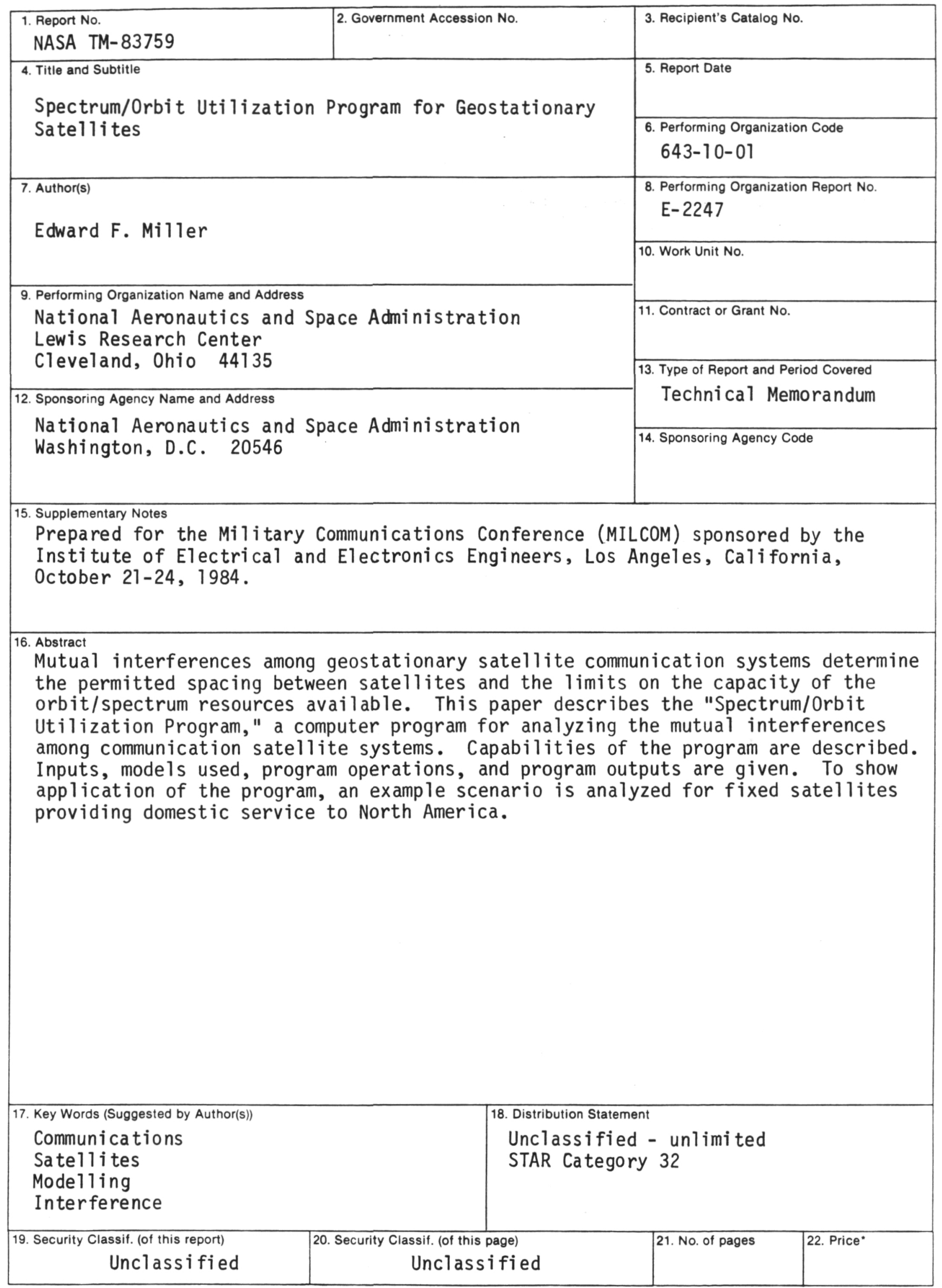


National Aeronautics and Space Administration

Washington, D.C.

20546

Official Business

Penalty for Private Use, $\mathbf{5 3 0 0}$
SAECIAL FOUATH CLASS MAIL BOOK

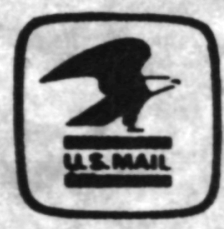

Poetage and Fees Paid National Aeronoutics and Spece Administration NASA-451 